\title{
Investigation of the Reduction of Graphene Oxide by Lithium Triethylborohydride
}

\author{
Guangyuan Xu, ${ }^{1,2,3}$ Jenny Malmström, ${ }^{1,2,3}$ Neil Edmonds, ${ }^{1}$ Neil Broderick, ${ }^{4}$ \\ Jadranka Travas-Sejdic, ${ }^{1,2,3}$ and Jianyong Jin ${ }^{1,2}$ \\ ${ }^{1}$ School of Chemical Sciences, University of Auckland, 23 Symonds Street, Auckland 1142, New Zealand \\ ${ }^{2}$ The MacDiarmid Institute for Advanced Materials and Nanotechnology, Wellington 6140, New Zealand \\ ${ }^{3}$ Polymer Electronics Research Centre (PERC), School of Chemical Sciences, University of Auckland, 23 Symonds Street, \\ Auckland 1142, New Zealand \\ ${ }^{4}$ Department of Physics, University of Auckland, 23 Symonds Street, Auckland 1142, New Zealand
}

Correspondence should be addressed to Jenny Malmström; j.malmstrom@auckland.ac.nz and Jianyong Jin; j.jin@auckland.ac.nz

Received 30 August 2015; Revised 7 December 2015; Accepted 16 December 2015

Academic Editor: Alessandro Pegoretti

Copyright (c) 2016 Guangyuan Xu et al. This is an open access article distributed under the Creative Commons Attribution License, which permits unrestricted use, distribution, and reproduction in any medium, provided the original work is properly cited.

\begin{abstract}
The chemical reduction of a wet colloidal suspension of graphene oxide is a cost-effective and adaptable method for large scale production of "quasi" graphene for a wide variety of optoelectronic applications. In this study, modified Hummers' procedure was used to synthesize high quality graphene oxide at $50^{\circ} \mathrm{C}$. This modified protocol thus eliminates the potentially hazardous second hightemperature step in Hummers' method for the production of GO. Furthermore, the reduction of graphene oxide by lithium triethylborohydride is demonstrated for the first time. According to FT-IR, UV-Vis, TGA, Raman, SEM/EDS, and AFM results, the reduced graphene oxide ( $\mathrm{LiEt}_{3} \mathrm{BH}-\mathrm{RGO}$ ) has properties comparable to other reduced graphene oxide products reported in the literature.
\end{abstract}

\section{Introduction}

Since its discovery and successful isolation by Novoselov et al. [1] in 2004, graphene and its related carbon materials have been extensively studied and have become an important materials research platform, potentially having a high impact on many areas of nanotechnology and material science in the 21 st century [2]. Graphene possesses tremendous mechanical, thermal, and electronic properties, which can be attributed to their large in-plane $\pi$-conjugation, nanoscale thickness and two-dimensional structure $[3,4]$. A wide range of applications can be found in the fields of lithium-ion batteries $[5,6]$, super capacitors [7], solar cells [8], polymer nanocomposites [9] and even as sea water desalination membranes [10, 11].

Among all methods of graphene preparation, "bottomup" methods such as chemical vapour deposition (CVD) [12] and the epitaxial growth method [13] demand significant capital investment which could translate to high production costs for scale-up of graphene production. Alternatively, the "top-down" strategy is promising to achieve inexpensive large scale synthesis of graphene. The common approaches include micromechanical exfoliation of graphite [1], liquidphase exfoliation of graphite [14], and the most popular wet chemistry method via a graphene oxide (GO) "intermediate." The reduction of GO can be achieved by chemical reducing agents [15], photo and thermal reduction [16], and bacterial reduction [17].

Dozens of chemical reducing agents have been reported to eliminate oxygen containing functional groups on GO and restore $\mathrm{sp}^{2}$ carbon networks. The list includes hydrazine [18], carbon monoxide [19], hydriodic acid [15], $\mathrm{SOCl}_{2}$ [20], alcohol [21], $\mathrm{Na}-\mathrm{NH}_{3}$ solution [22], aluminum powder [23], $\mathrm{NaOH}$ [24], thiourea [25], ascorbic acid [26], glucose [27], pphenylenediamine [28], $\mathrm{NaBH}_{4}$ [29], and lithium aluminum hydride [30]. Several previously reported reducing agents have some limitations such as high toxicity or weak reducing power; therefore, efforts are being made to identify new reduction routes. In this paper, a new reduction approach for $\mathrm{GO}$ using lithium triethylborohydride $\left(\mathrm{LiEt}_{3} \mathrm{BH}\right.$, also known as super hydride) is investigated. From the literature $[31,32]$, 


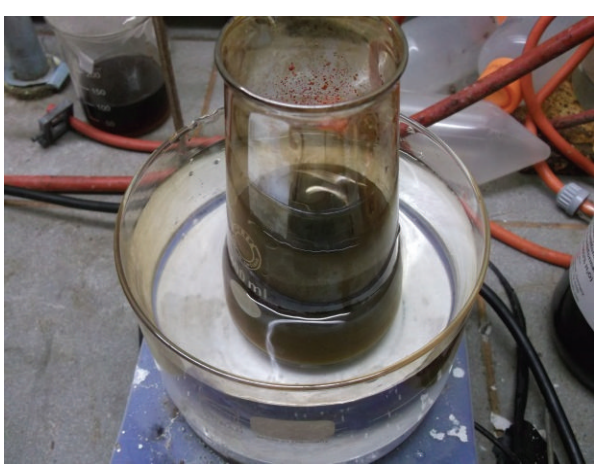

(a)

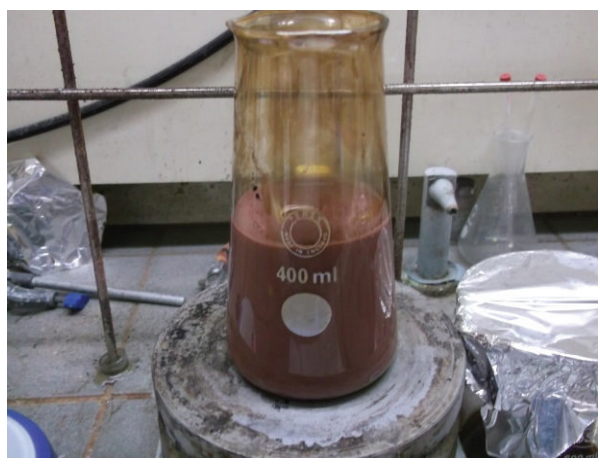

(c)

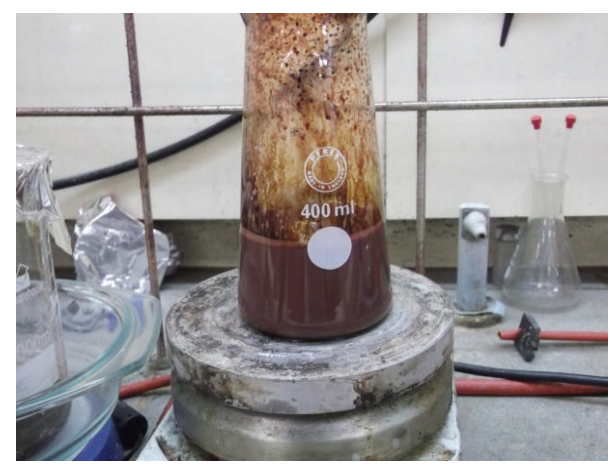

(b)

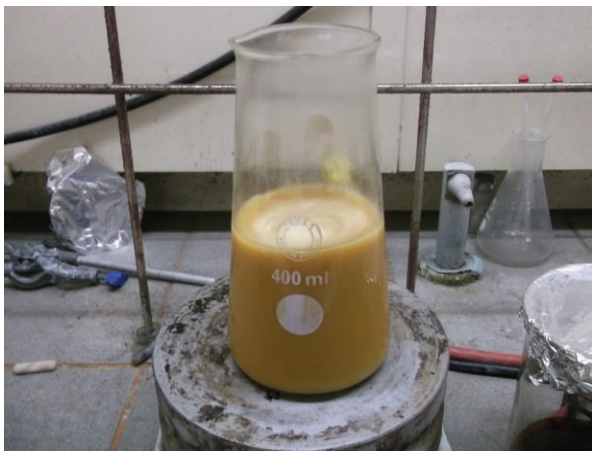

(d)

Figure 1: (a) Reaction suspension in sulfuric acid; (b) reaction paste after $24 \mathrm{~h}$ oxidation at $50^{\circ} \mathrm{C}$; (c) the reaction mixture quenched with ice; (d) final reaction mixture after $\mathrm{H}_{2} \mathrm{O}_{2}$ addition.

lithium triethylborohydride is assumed to be a powerful agent to reduce carboxylic acids, carbonyl groups, and epoxy groups. One of the additional advantages for $\mathrm{LiEt}_{3} \mathrm{BH}$ reduction is that it is less toxic than lithium aluminum hydride. The rGO by lithium triethylborohydride will be abbreviated as $\mathrm{LiEt}_{3} \mathrm{BH}-\mathrm{RGO}$. In addition, in this work, the GO was prepared at a reaction temperature of $50^{\circ} \mathrm{C}$, the original Hummers' method used $35^{\circ} \mathrm{C}$ [33]; therefore, $50^{\circ} \mathrm{C}$ is designated as medium temperature Hummer GO (MTH-GO). This method importantly removes the undesirable hightemperature step $\left(98^{\circ} \mathrm{C}\right)$ of the potentially explosive reaction mixture used. A series of techniques including solid state Nuclear Magnetic Resonance (ssNMR), Fourier Transform Infrared (FTIR) spectroscopy, ultraviolet-visible spectroscopy (UV-Vis), Raman spectroscopy (Raman), X-ray Photoelectron Spectroscopy (XPS), Thermal Gravimetric Analysis (TGA), Atomic Force Microscopy (AFM), Scanning Electron Microscopy (SEM), and energy-dispersive X-ray spectroscopy (EDS) were applied to characterize the synthesized MTH-GO and $\mathrm{LiEt}_{3} \mathrm{BH}-\mathrm{RGO}$.

\section{Experimental Details}

2.1. Materials. Graphite powder (average particle size $<45 \mu \mathrm{m}$, Catalogue \#496596) and lithium triethylborohydride $\left(\mathrm{LiEt}_{3} \mathrm{BH}, 1 \mathrm{M}\right.$ in THF solution, Catalogue \#179728) were purchased from Sigma Aldrich. Concentrated sulphuric acid $\left(\mathrm{H}_{2} \mathrm{SO}_{4}\right.$, ACS grade, $\left.98 \%\right)$ and hydrochloric acid $(\mathrm{HCl}$,
ACS grade, 36.5-38\%) were purchased from J. T. Baker. Potassium permanganate $\left(\mathrm{KMnO}_{4}, \mathrm{AR}\right.$ grade) and $35 \%$ hydrogen peroxide $\left(\mathrm{H}_{2} \mathrm{O}_{2}\right.$, LR food grade) were purchased from ECP. Sodium nitrate $\left(\mathrm{NaNO}_{3}, \mathrm{AR}\right.$ grade $)$ was purchased from UNIVAR.

2.2. Synthesis of MTH-GO. Graphite $(2.0 \mathrm{~g}, 0.1667 \mathrm{~mol})$ was firstly microwaved in $1000 \mathrm{~W}$ microwave oven for $10 \mathrm{~s}$ to expand the layers, the graphite turned red during this treatment [34]. The graphite and $\mathrm{NaNO}_{3}(2.0 \mathrm{~g}, 0.0235 \mathrm{~mol})$ were then added to the concentrated $\mathrm{H}_{2} \mathrm{SO}_{4}(120 \mathrm{~mL})$ and the mixture was magnetically stirred together in an ice water bath. $\mathrm{KMnO}_{4}(12.0 \mathrm{~g}, 0.0759 \mathrm{~mol})$ was then added to the suspension very slowly with vigorous stirring for 15 minutes. As shown in Figure 1(a), the color of the mixture became dark green. The mixture was then transferred to a preheated oil bath at $50^{\circ} \mathrm{C}$ to react for 24 hours. As the oxidation proceeded, the suspension became a very thick paste where the color changed from dark green to brownish purple (Figure 1(b)); this is similar to the color reported in the literature [33].

After oxidation under the medium temperature was completed, the mixture was quenched with $100 \mathrm{~g}$ of ice (made from distilled water). As the addition of ice progressed, the color of the mixture slowly turned to bright purple (Figure $1(\mathrm{c})$ ). Finally, $35 \% \mathrm{H}_{2} \mathrm{O}_{2}(12 \mathrm{~mL})$ was added in the suspension to consume the residual permanganate. If the synthesis is successful [33], the final graphite oxide mixture should be bright yellow as shown in Figure 1(d). 
2.3. Purification of $M T H-G O .37 \% \mathrm{HCl}(100 \mathrm{~mL})$ was added to the product mixture and centrifuged at $8000 \mathrm{rpm}$ for $10 \mathrm{~min}$. The clear supernatant was discarded and the precipitate was washed with $100 \mathrm{~mL}$ of ethanol followed by $100 \mathrm{~mL}$ of distilled water. The resulting graphite oxide solid was dialyzed (molecular weight cut-off $=1000 \mathrm{Da}$, Spectra/Por) for four days until the conductivity decreased to $10 \mu \mathrm{S} / \mathrm{cm}$ to ensure the complete removal of ionic impurities. To obtain the graphene oxide, the graphite oxide product was exfoliated in an ultrasound bath (100 watts) for 2 hours as a $1000 \mathrm{~mL}$ aqueous dispersion.

The graphene oxide suspension was concentrated by rotoevaporation at $50^{\circ} \mathrm{C}$, and approximately $800 \mathrm{~mL}$ water was removed. The concentrated graphene oxide suspension was ultrasonicated again for $30 \mathrm{mins}$ and centrifuged at $8000 \mathrm{rpm}$ for $5 \mathrm{~min}$, and the sediment (assumed to be less exfoliated graphite oxide) was discarded. The supernatant was kept and dried in vacuum at $50^{\circ} \mathrm{C}$ for five days to obtain high quality MTH-GO $(0.6 \mathrm{~g}, 30 \%$ yield).

2.4. Synthesis of $\mathrm{LiEt}_{3} B H-R G O$. Dry MTH-GO powder $(30 \mathrm{mg})$ was added to anhydrous THF $(40 \mathrm{~mL})$ and ultrasonicated for two hours to form a relatively uniform dispersion; lithium triethylborohydride solution $\left(\mathrm{LiEt}_{3} \mathrm{BH}\right)(30 \mathrm{~mL}$, $1 \mathrm{~mol} / \mathrm{L}$ in THF) was then added dropwise at $0^{\circ} \mathrm{C}$. Bubbles were observed initially and to complete the reaction the suspension was refluxed overnight under nitrogen at $66^{\circ} \mathrm{C}$. The unknown amount of unreacted $\mathrm{LiEt}_{3} \mathrm{BH}$ was quenched with ethanol $(10 \mathrm{~mL})$ and deionized water $(10 \mathrm{~mL})$ at $0^{\circ} \mathrm{C}$. The $\mathrm{LiEt}_{3} \mathrm{BH}-\mathrm{RGO}$ product $(14.6 \mathrm{mg}$ ) was isolated by filtration under slightly acidic $\mathrm{pH}$ condition and washed with acetone and deionized water three times and dried at $80^{\circ} \mathrm{C}$ under vacuum for five days ( $48 \%$ yield).

2.5. Characterization Techniques. ${ }^{13} \mathrm{C}$ solid state NMR analyses were carried out on a dry sample using a Bruker Avance 300 standard bore magnet system operating at $300.13 \mathrm{MHz}$ proton frequency $(7.05 \mathrm{~T})$. The spectra were obtained by using SPE HPDEC (single pulse excitation with high power decoupling) technique. The magic angle was adjusted by maximizing the sidebands of the ${ }^{79} \mathrm{Br}$ signal of a $\mathrm{KBr}$ sample. Atomic Force Microscopy (AFM) was performed using an Asylum Research Cypher ES instrument (Oxford Instruments, US). Images were acquired in air using tapping mode with a gold coated NSG 10 probe (resonance frequency $255 \mathrm{kHz}$ ) from NT-MTD (Russia). The cantilever was driven using blueDrive photothermal excitation. During the postprocessing of images, the background of the images was flattened, while the features were preserved by masking. Scanning Electron Microscopy (SEM) and energy-dispersive $\mathrm{X}$-ray spectroscopy (EDS) analysis were conducted using a Quanta 200F (FEI, US) operating in variable pressure ESEM mode. It is equipped with an EDAX brand EDS detector with a SiLi Lithium Drifted Super Ultrathin Window. The samples were coated with a Quorum Q150RS sputter coater to provide platinum coating. The XPS data were collected on a Kratos Axis Ultra DLD equipped with a hemispherical electron energy analyzer. Spectra were excited using monochromatic $\mathrm{Al} \mathrm{K} \alpha \mathrm{X}$-rays $(1486.69 \mathrm{eV})$ with the $\mathrm{X}$-ray source operating at $150 \mathrm{~W}$. This instrument illuminates a large area on the surface and then using hybrid magnetic and electrostatic lenses collects photoelectrons from the desired location on the surface. In this case, the analysis area was 300 by $700 \mu \mathrm{m}$ spot (=hybrid/slot). Data evaluation and peak fitting were performed using the CasaXPS software. Thermal Gravimetric Analysis (TGA) were performed using a TGA-50 (Shimadzu, Japan) under argon (flow rate of $50 \mathrm{~mL} / \mathrm{min}$ ) at a heating rate of $1^{\circ} \mathrm{C} / \mathrm{min}$ from 30 to $800^{\circ} \mathrm{C}$ for graphene oxide and a heating rate of $5^{\circ} \mathrm{C} / \mathrm{min}$ from 30 to $800^{\circ} \mathrm{C}$ for reduced graphene oxide. The Raman spectra were recorded on a Renishaw 1000 Raman Imaging Microscope consisting of a single grating spectrograph with holographic notch filter to remove Rayleigh scattered light, Leitz microscope, and air-cooled CCD array detector. The excitation laser was a SpectraPhysics Air-Cooled Argon ion laser with a blue emission line at $488 \mathrm{~nm}$ at $25 \mathrm{~mW}$ in combination with 2400 lines $/ \mathrm{mm}$ grating. Fourier Transform Infrared (FTIR) analyses were performed using the Smart Orbit Diamond Attenuated Total Reflection (ATR) single reflection accessory of a Thermo Electron Nicolet 8700 FTIR spectrometer. The signals were processed using the OMNIC spectroscopic software.

\section{Results and Discussion}

3.1. Synthesis and Processing of MTH-GO. The oxidation temperature is the most critical parameter in graphite oxidation. Generally, the temperature of $35^{\circ} \mathrm{C}$ is used in the original Hummers' method. In this study, a reaction temperature of $50^{\circ} \mathrm{C}$ was used and the postheating step $\left(98^{\circ} \mathrm{C}\right.$ for $\left.15 \mathrm{~min}\right)$ was eliminated. Increasing the reaction temperature to $50^{\circ} \mathrm{C}$ could enhance the rate and degree of oxidation. In Tour's improved method [35], $50^{\circ} \mathrm{C}$ was also shown to be an effective reaction temperature for the oxidation of graphite. However, the appropriate safe temperature should never exceed $55^{\circ} \mathrm{C}$ as manganese heptoxide $\left(\mathrm{Mn}_{2} \mathrm{O}_{7}\right)$ is explosive at temperatures above that. For the reader's benefit, the colour changes during the synthesis are illustrated in Figures 1(a)-1(d). As shown in Figure 2, the MTH-GO can be used to prepare partially transparent and free-standing membranes using vacuum filtration [36], with excellent mechanical properties including flexibility (Figures 2(a) and 2(b)). The Tyndall effect can be observed by the laser scattering in the fine colloidal MTH-GO aqueous suspension (Figure 2(c)). Finally, MTH-GO can be coated onto polyethylene terephthalate (PET) films for laser inscription (Figure 2(d)).

3.2. Chemical Reduction by Lithium Triethylborohydride $\left(\mathrm{LiEt}_{3} \mathrm{BH}\right)$. In the "tool box" of organic chemistry, the reduction using hydrides is well understood [37]. Sodium borohydride $\left(\mathrm{NaBH}_{4}\right)$ is a common reducing agent in synthetic chemistry. When used in the presence of carbonyl groups, the borohydride can carry out a hydride transfer reaction to form an oxyanion and $\mathrm{BH}_{3}$ molecule. However, the reduction of borohydride is limited by the types of carbonyl. Gao and coauthors [38] reported a complete reduction process using $\mathrm{NaBH}_{4}$ as the first step of a three-step synthesis. After treatment of sulfuric acid and thermal annealing, the $\pi$ conjugated structure was effectively restored. Only less than 


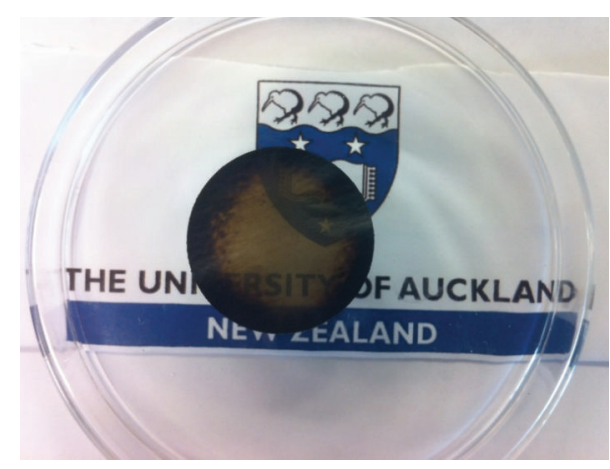

(a)

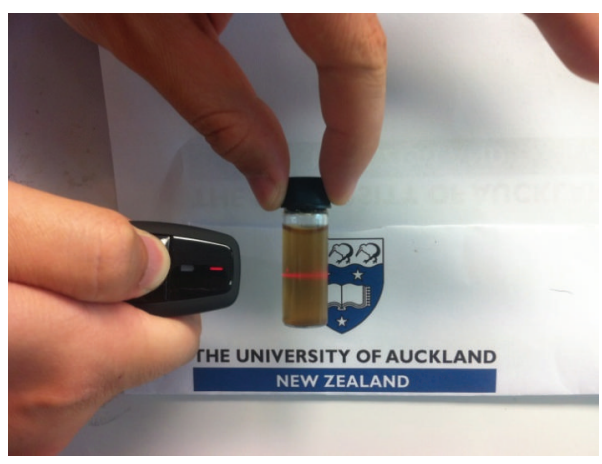

(c)

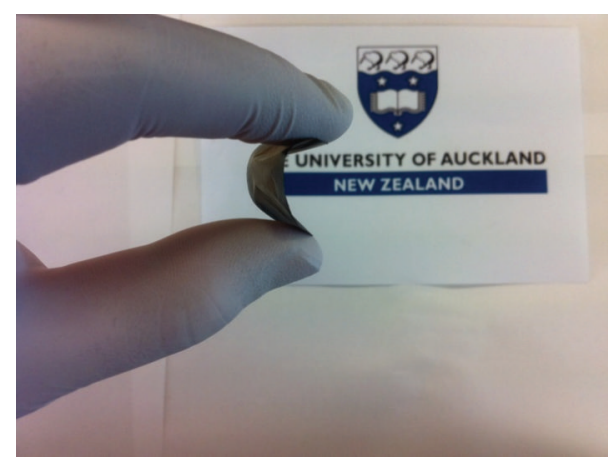

(b)

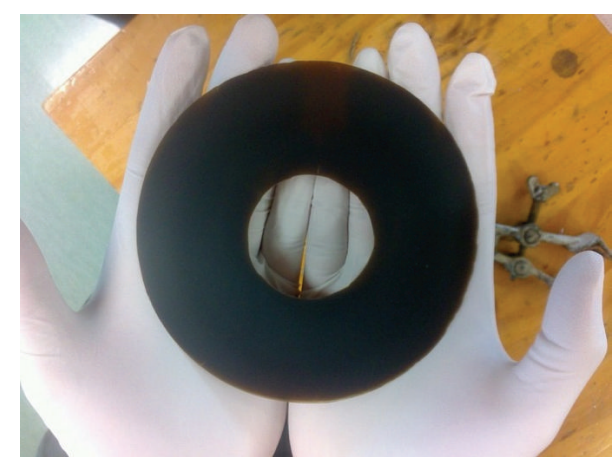

(d)

FIGURE 2: (a) Partially transparent MTH-GO membrane; (b) free-standing and flexible MTH-GO membrane; (c) Tyndall effect of MTH-GO dispersion in water; (d) MTH-GO coating on PET film.

$0.5 \mathrm{wt} \%$ of nitrogen and sulfur was left, which was more effective than other reduction methods.

Another common hydride is lithium aluminium hydride (LAH), one of the strongest reducing agents in organic synthetic chemistry. Ambrosi et al. [30] recently reported using lithium aluminum hydride to reduce graphene oxide and achieve a C/O ratio of 12 .

Krishnamurthy and Brown [32] suggested that $\mathrm{LiEt}_{3} \mathrm{BH}$ is a strong reducing agent available for unselectively reducing carboxylic acids, carbonyls, and epoxy groups to corresponding hydroxyl groups. $\mathrm{LiEt}_{3} \mathrm{BH}$ has recently been reported in the production of thermally exfoliated graphene- $\mathrm{Li}_{2} \mathrm{~S}$ nanocomposite, where sulfur loaded graphene was chemically modified using $\mathrm{LiEt}_{3} \mathrm{BH}$ to form uniformly dispersed $\mathrm{Li}_{2} \mathrm{~S}$ nanoparticles [39]. Here, we show results from the chemical reduction of graphene oxide using this unselective reducing agent.

\subsection{Characterization of $M T H-G O$ and $\mathrm{LiEt}_{3} B H-R G O$. A} variety of techniques were employed to identify MTH-GO's chemical structure and composition. Firstly, the solid state ${ }^{13} \mathrm{C}$ NMR result is illustrated in Figure 3, the major peak representing epoxide groups (C-O-C) is located at $61 \mathrm{ppm}$. The carbon adjacent to hydroxyl groups $(\mathrm{C}-\mathrm{OH})$ was shifted to $70 \mathrm{ppm}$; this peak only appears as a small shoulder embedded within dominant epoxide groups [38, 40]. Other carbonaceous signals can also be distinguished and stand for lactol groups (O-C-O) at $101 \mathrm{pm}$, lactol carbonyls, and esters

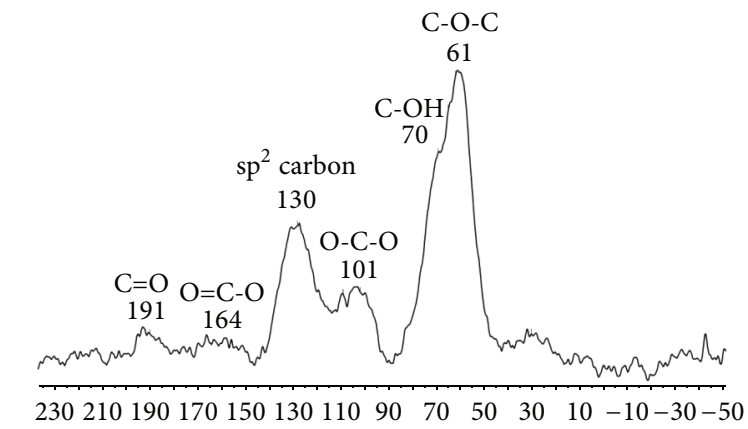

Figure 3: Solid state ${ }^{13} \mathrm{C}$ NMR spectrum of MTH-GO sample.

near $164 \mathrm{ppm}$ and ketone carbonyl groups at $191 \mathrm{ppm}$. The remaining broad peak at $130 \mathrm{ppm}$ was designated to the $\mathrm{sp}^{2}$ carbon from original graphitic structure. Those findings are consistent with the results reported in the literature $[38,40]$.

Due to the limited solubility of graphene oxide, quantifying the $\mathrm{C} / \mathrm{O}$ ratio using standard techniques (such as solution NMR) is not possible. Therefore, XPS was used to measure the chemical state of the element carbon at the graphene oxide surface. The C1s spectrum of MTH-GO (Figure 4) revealed five peaks, by deconvoluting that corresponds to the following functional groups including $\mathrm{sp}^{2}$ carbon $(\mathrm{C}=\mathrm{C}, 283.4 \mathrm{eV}), \mathrm{sp}^{3}$ carbon (C-C, 284.4 eV), epoxy/hydroxyls (C-O, $286.4 \mathrm{eV})$, carbonyl $(\mathrm{C}=\mathrm{O}, 287.4 \mathrm{eV})$, and carboxylates $(\mathrm{O}-\mathrm{C}=\mathrm{O}$, 


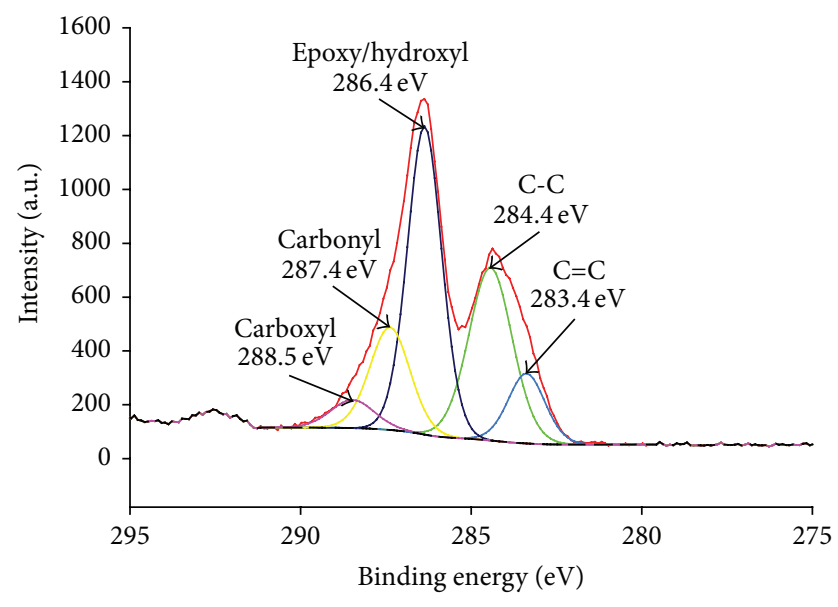

Figure 4: C1s XPS spectra of MTH-GO.

$288.5 \mathrm{eV}$ ). The higher energy peak at $\approx 292 \mathrm{eV}$ is attributed to $\pi-\pi^{*}$ shakeup satellite of the $\mathrm{sp}^{2}$ carbon. The binding energies of these functional groups were consistent with literature results [30]. Overall, the integration of combined oxidized carbon and that of graphitic carbon (both $\mathrm{sp}^{2}$ and $\mathrm{sp}^{3}$ carbons) gives a ratio of oxidized to nonoxidized carbon species of approximately 1.6; that is, $60 \%$ of the carbon is in a oxidized form (in agreement with the overall $\mathrm{O} / \mathrm{C}$ ratio of 0.6 derived from the survey spectra), which is similar to the reported degree of oxidation by other methods [35]. Near edge X-ray absorption fine structure (NEXAFS) measurements were also recently employed to compare the properties of graphene oxide produced by Hummers' and Tour methods, indicaing a higher incidence of $\mathrm{C}-\mathrm{OH}$ and $\mathrm{C}=\mathrm{O}$ functional groups in the material prepared by Tours' method [41].

The morphology of both MTH-GO and $\mathrm{LiEt}_{3} \mathrm{BH}-\mathrm{RGO}$ was investigated using AFM and SEM. For AFM imaging, a very dilute solution of $\mathrm{MTH}-\mathrm{GO}$ or $\mathrm{LiEt}_{3} \mathrm{BH}-\mathrm{RGO}$ was transferred onto a freshly cleaved mica. As shown in Figure 5, layers of MTH-GO are clearly visible at the surface, some overlapping each other and some curling up [35].

The monolayer nature of graphene oxide and reduced graphene oxide was confirmed by AFM (Figure 5). The thickness of both MTH-GO and $\mathrm{LiEt}_{3} \mathrm{BH}-\mathrm{RGO}$ was measured from section analysis to be in the range of $1.1-1.5 \mathrm{~nm}$ (data from several images, example shown in Figure 5), with $\mathrm{LiEt}_{3} \mathrm{BH}-\mathrm{RGO}$ displaying more flexible/folded sheets. The $\mathrm{LiEt}_{3} \mathrm{BH}-\mathrm{RGO}$ flakes (shown in Figure 5(c)) display numerous hole defects. The formation of holes may be caused by the removal of oxygen groups from the carbon lattice during the reduction resulting in vacancies forming on monolayer graphene sheets [42].

SEM was also performed to give further insight into the morphology and to compare the $\mathrm{O} / \mathrm{C}$ ratio for $\mathrm{MTH}-\mathrm{GO}$ and $\mathrm{LiEt}_{3} \mathrm{BH}-\mathrm{RGO}$ (Figure 6 shows two different magnifications for each sample type). The SEM has shown an apparent change to a more wrinkled morphology after the reduction, resembling a very thin curtain, consistent with AFM.
EDS (energy-dispersive X-ray spectroscopy) was used to characterize the elemental composition of MTH-GO and $\mathrm{LiEt}_{3} \mathrm{BH}-\mathrm{RGO}$. The atomic ratio of carbon to oxygen in MTH-GO was $\sim 3.7$ which increased to $\sim 10.8$ after the reduction. This is consistent with values reported previously $(\sim 8.8-$ 12.5) [43] in the case of using reducing agent for reduction of MTH-GO. In addition, $\sim 1.7$ At \% of sulfur was detected in MTH-GO, which may be residual sulfuric acid from the Hummer based preparation method. The sulfur content was significantly reduced in the $\mathrm{LiEt}_{3} \mathrm{BH}-\mathrm{RGO}(\sim 0.22 \mathrm{At} \%)$.

The UV-Vis characterization of MTH-GO and $\mathrm{LiEt}_{3} \mathrm{BH}-$ RGO (Figure 7) shows a prominent peak at $228 \mathrm{~nm}$ with shoulder band around $300 \mathrm{~nm}$, this mostly originates from the conjugated structures of unoxidized graphitic domains ( $\mathrm{sp}^{2} \mathrm{C}=\mathrm{C}$ bond) $[35,44]$. The shoulder peak originates from $\mathrm{n}-\pi^{*}$ transitions of the carbonyl groups; these were clearly observed which is an excellent indication of the high degree of oxidation in the MTH-GO sample [44]. The absorption peak of $\mathrm{LiEt}_{3} \mathrm{BH}-\mathrm{RGO}$ dispersion was shifted to $\sim 260 \mathrm{~nm}$ from $228 \mathrm{~nm}$ after the chemical reduction. This could suggest that the $\mathrm{LiEt}_{3} \mathrm{BH}$ reduction is able to restore the electronic conjugation structure, as expected [44].

Figure 8 compares the FTIR spectra of MTH-GO and $\mathrm{LiEt}_{3} \mathrm{BH}-\mathrm{RGO}$. For MTH-GO, a very broad, composite peak between 3000 and $3600 \mathrm{~cm}^{-1}$ was observed due to the stretching vibration of hydroxyl group and physisorbed water. The secondary characteristic absorbance peaks from MTH-GO include a peak at $1736 \mathrm{~cm}^{-1}$ corresponding to the $\mathrm{C}=\mathrm{O}$ stretching vibration from the carboxyl group at the periphery of GO sheets and a band at around $1220 \mathrm{~cm}^{-1}$ assigned to the $\mathrm{C}-\mathrm{O}-\mathrm{C}$ stretching vibration from epoxy groups on the basal plane. The FTIR spectrum of MTH-GO also displayed the presence of a peak at $1633 \mathrm{~cm}^{-1}$, attributed as an additive peak of both the bending mode of associated water and the contribution from the $\mathrm{C}=\mathrm{C}\left(\mathrm{sp}^{2}\right)$ bonds (seen as a shoulder around $\left.1580 \mathrm{~cm}^{-1}\right)$. The contribution from the $\mathrm{C}=\mathrm{C}\left(\mathrm{sp}^{2}\right)$ modes is seen to vastly increase upon the reduction to $\mathrm{LiEt}_{3} \mathrm{BH}-\mathrm{RGO}$ as expected. The FTIR-ATR characterization of MTH-GO was consistent with graphene oxide prepared by other methods [35]. After $\mathrm{LiEt}_{3} \mathrm{BH}$ chemical reduction, all absorbance intensities associated with oxygenous functional groups (carbonyl, epoxide, and hydroxyl, etc.) were decreased dramatically, showing that the MTH-GO was reduced to the $\mathrm{LiEt}_{3} \mathrm{BH}-\mathrm{RGO}$. The relative strong band at $1586 \mathrm{~cm}^{-1}$ is the $\mathrm{C}=\mathrm{C}$ stretching of $\mathrm{sp}^{2}$ carbon from graphitic structures, with the water mode at $1633 \mathrm{~cm}^{-1}$ present in MTH-GO being significantly reduced $[27,45]$. The methyl and ethyl C-H stretching vibrations are seen to arise at $2800 \mathrm{~cm}^{-1}-3000 \mathrm{~cm}^{-1}$ as the functional groups in MTH-GO are reduced. The absorbance between $3100 \mathrm{~cm}^{-1}$ and $3500 \mathrm{~cm}^{-1}$ has been significantly diminished and corresponds to any residual hydroxyl groups or physisorbed water.

To probe more information on the quality of the $\mathrm{LiEt}_{3} \mathrm{BH}$ RGO by our lithium triethylborohydride method, Raman spectra of MTH-GO and $\mathrm{LiEt}_{3} \mathrm{BH}-\mathrm{RGO}$ (Figure 9) were also collected and compared. The Raman spectrum of graphene is dominated by two features: the $G$ mode $\left(\approx 1575 \mathrm{~cm}^{-1}\right)$ 


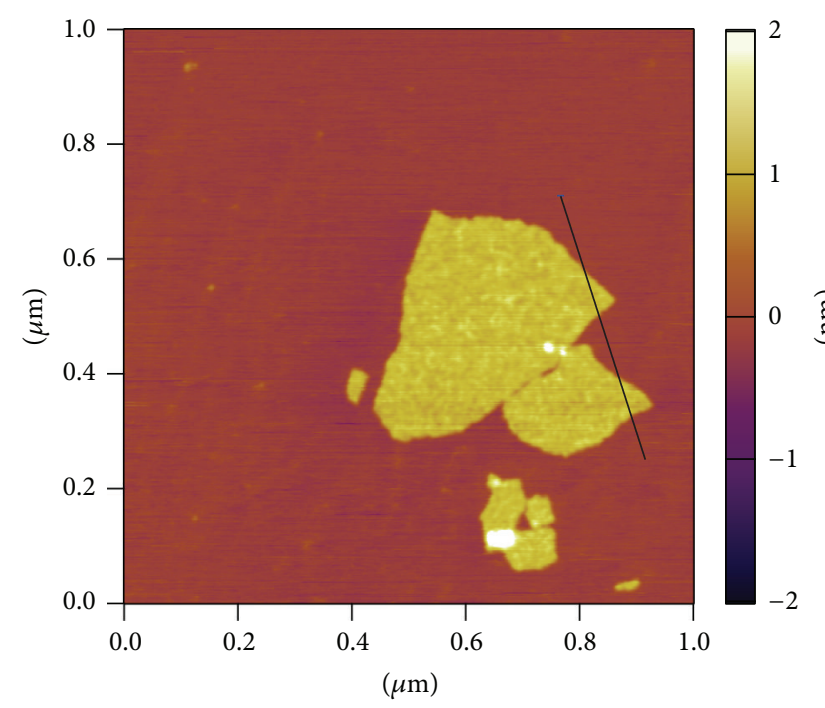

(a)

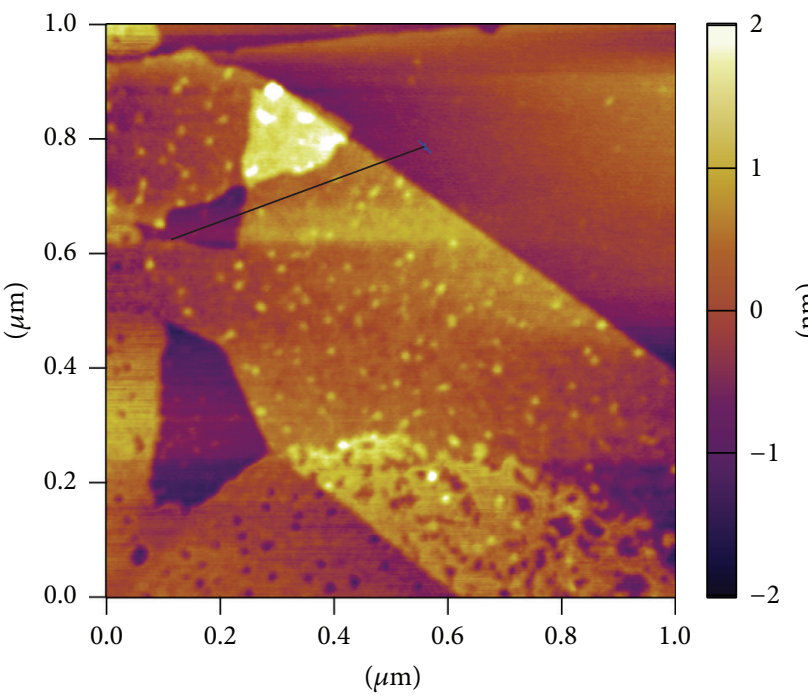

(c)

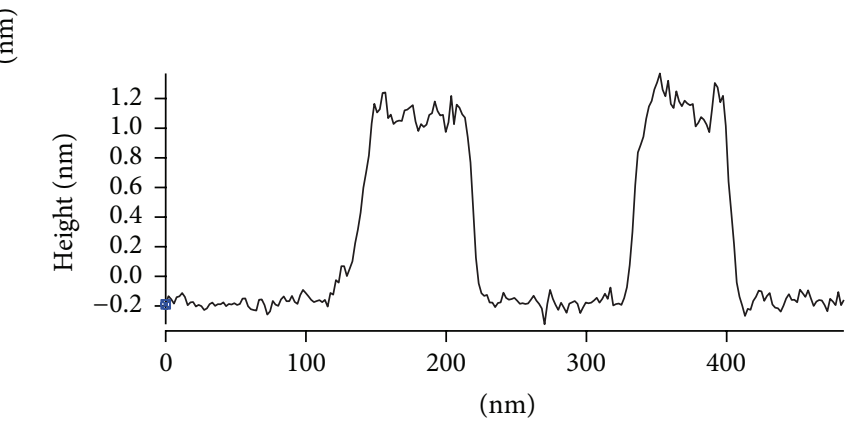

(b)

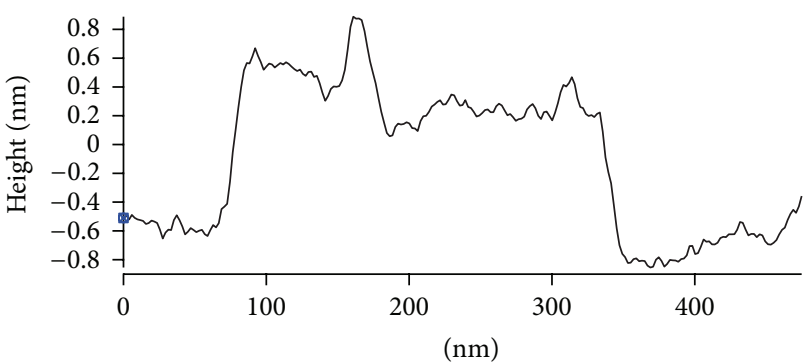

(d)

FIGURE 5: Tapping mode AFM image (a) shows the topography of MTH-GO and its height profile in (b). After $\mathrm{LiEt}_{3} \mathrm{BH}$ reduction, $\mathrm{LiEt}_{3} \mathrm{BH}-$ RGO sheets were diluted and ultrasonicated in water. Image (c) shows the topography of $\mathrm{LiEt}_{3} \mathrm{BH}-\mathrm{RGO}$ suspension on mica and its crosssection analysis in (d).

and the $\mathrm{D}$ mode $\left(\approx 1350 \mathrm{~cm}^{-1}\right)$, where the $\mathrm{D}$ mode relates to disorder in the $\mathrm{sp}^{2}$ hybridized carbon system [27]. Both samples investigated here displayed two main absorbance peaks around $1355 \mathrm{~cm}^{-1}$ and $1600 \mathrm{~cm}^{-1}$, corresponding to the $\mathrm{D}$ and $\mathrm{G}$ bands, respectively. The $\mathrm{D}$ band displays a shift from $1353 \mathrm{~cm}^{-1}$ to $1359 \mathrm{~cm}^{-1}$ after the reduction. This correlates to the loss of associated water in-between the layers of $\mathrm{sp}^{2}$ hybridized carbon. In terms of peak intensity, the D band increased with concomitant decrease of the $G$ band after lithium triethylborohydride reduction. Clearly, the reduction process transformed the structure of MTH-GO and produced domains of chemically reduced graphene. The $I_{\mathrm{D}} / I_{\mathrm{G}}$ ratio of $\mathrm{LiEt}_{3} \mathrm{BH}-\mathrm{RGO}$ was about 1.06 , while $I_{\mathrm{D}} / I_{\mathrm{G}}$ of MTH-GO is 0.85 , indicating a more disordered structure. This result is consistent with other reduction methods, such as alumina powder [23], hydriodic acid [15], and hydrothermal "green" approaches [46].

The successful reduction of MTH-GO with $\mathrm{LiEt}_{3} \mathrm{BH}$ was further supported by TGA results as shown in Figure 10. The major weight loss of MTH-GO took place at three temperature zones. Approximately $10 \%$ of weight loss occurred between $30^{\circ} \mathrm{C}$ and $100^{\circ} \mathrm{C}$ and was due to the evaporation of absorbed water. The labile oxygenous functional groups (about $25 \mathrm{wt} \%$ ) were eliminated between $140^{\circ} \mathrm{C}$ and $190^{\circ} \mathrm{C}$ with releasing $\mathrm{CO}_{2}$ and other small molecules. The third significant mass loss occurred from $500^{\circ} \mathrm{C}$ to $600^{\circ} \mathrm{C}$, which could be the pyrolysis of residual debris. Ultimately, all components were nearly gone resulting in less than $20 \%$ char yield. The TGA characterization of MTH-GO was consistent with the result reported by Stankovich et al. [18]. 


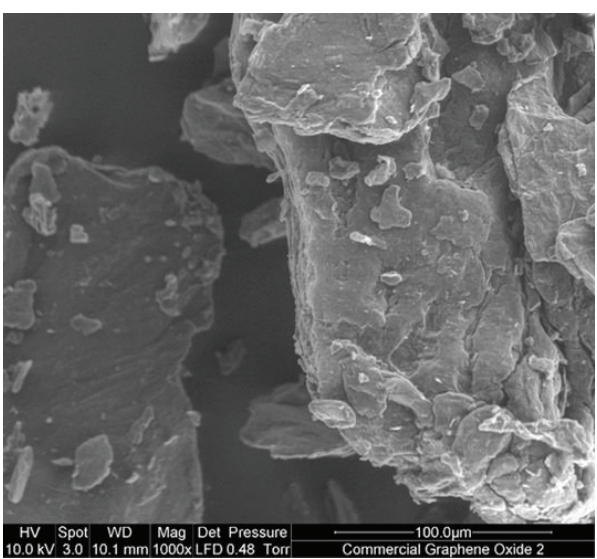

(a)

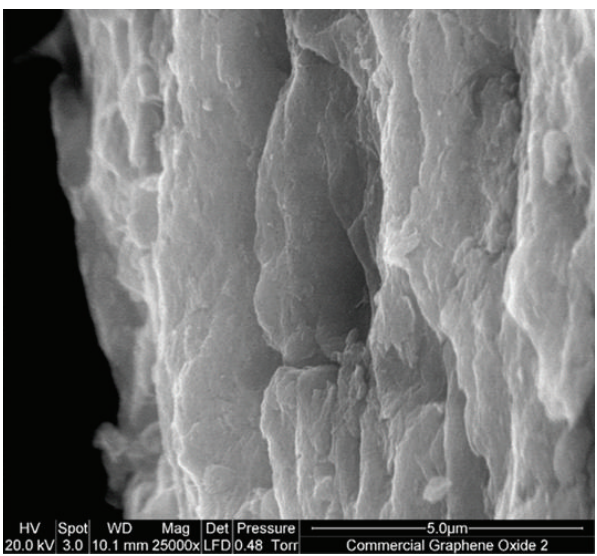

(b)

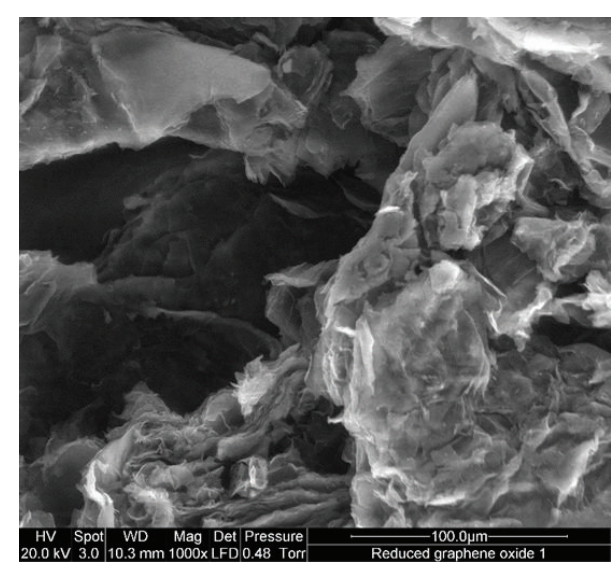

(c)

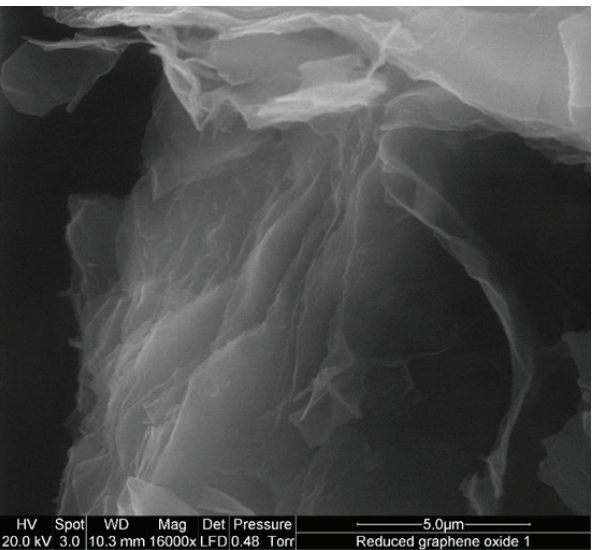

(d)

Figure 6: SEM images of MTH-GO before (a-b) and after (c-d) LiEt 3 BH reduction with a low magnification of 1000x (top row) or high magnification of $25000 \mathrm{x}$ (bottom row).

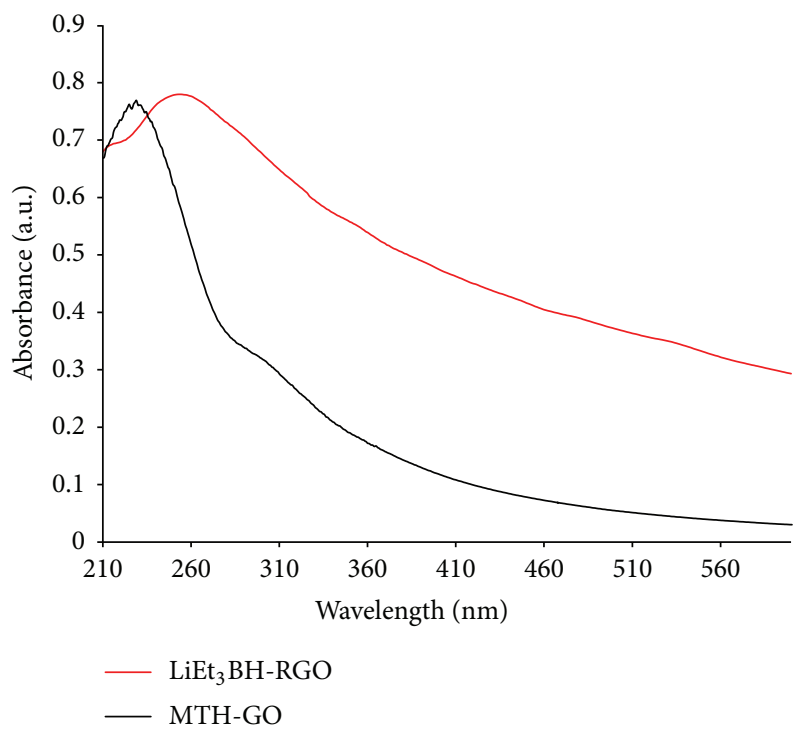

FIGURE 7: The UV-Vis spectra show the absorption change of MTH$\mathrm{GO}$ and $\mathrm{LiEt}_{3} \mathrm{BH}-\mathrm{RGO}$ after $\mathrm{LiEt}_{3} \mathrm{BH}$ reduction.

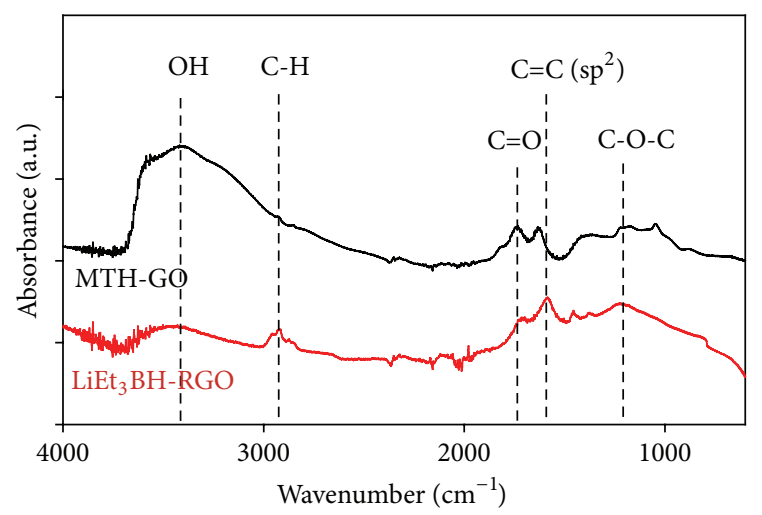

Figure 8: FTIR-ATR spectra of MTH-GO and LiEt ${ }_{3}$ BH-RGO.

The thermal decomposition graphene oxide usually releases gas vigorously. During a fast heating process, rapid thermal expansion could occur, potentially leading to mass loss as well as instrument damage [18]. Therefore, here we chose 


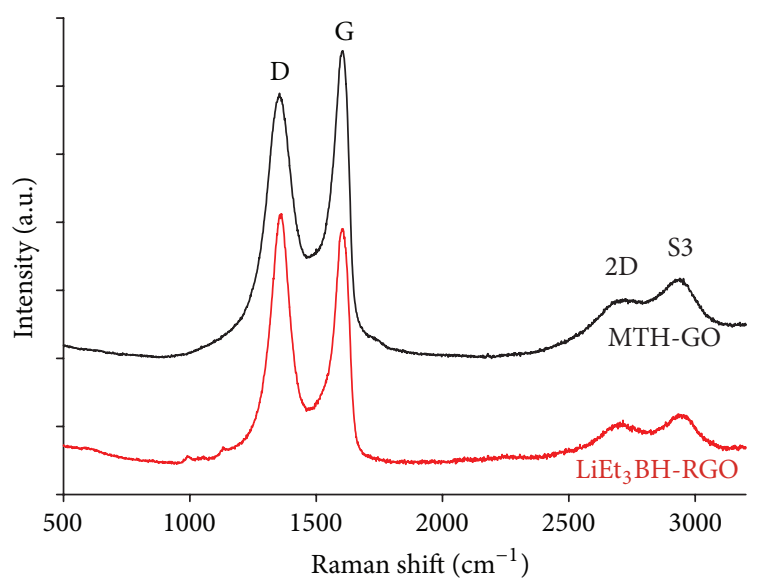

Figure 9: Raman spectra of MTH-GO and $\mathrm{LiEt}_{3} \mathrm{BH}-\mathrm{RGO}$ using $488 \mathrm{~nm}$ laser.

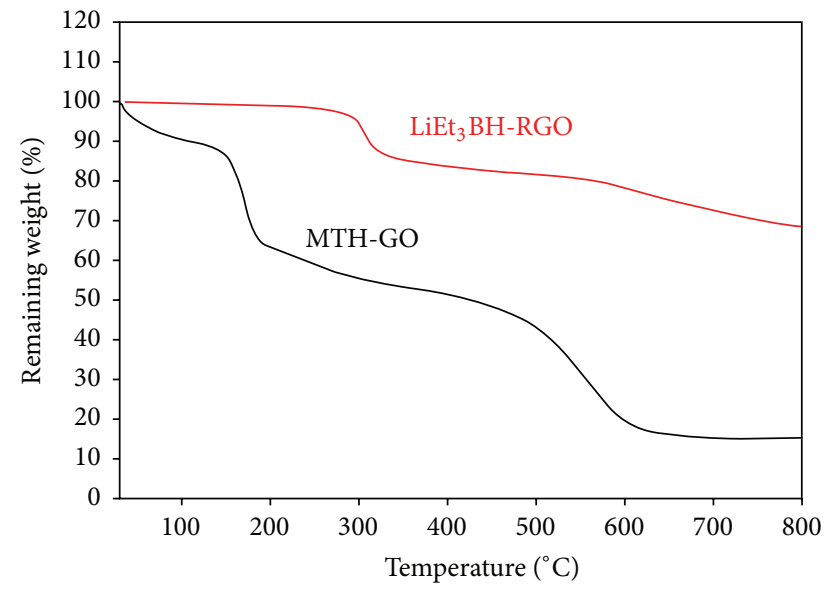

FIGURE 10: TGA investigation of decomposition behavior of MTHGO with a heating rate of $1^{\circ} \mathrm{C} / \mathrm{min}$ and $\mathrm{LiEt}_{3} \mathrm{BH}-\mathrm{RGO}$ with the heating rate of $5^{\circ} \mathrm{C} / \mathrm{min}$ (both under argon).

a relatively slow heating rate $\left(1^{\circ} \mathrm{C} / \mathrm{s}\right)$ to analyse $\mathrm{MTH}-\mathrm{GO}$ 's thermal decomposition [18].

In comparison, the TGA thermogram of $\mathrm{LiEt}_{3} \mathrm{BH}-\mathrm{RGO}$ shows significantly improved thermal stability compared to MTH-GO. Interestingly, while the remainder of the reduced graphene oxide gave featureless and progressive weight loss $[18,22]$, the $\mathrm{LiEt}_{3} \mathrm{BH}-\mathrm{RGO}$ had a noticeable weight loss which took place between 300 and $350^{\circ} \mathrm{C}$ as a result of the remaining oxygenous species. The overall weight loss of $\mathrm{LiEt}_{3} \mathrm{BH}-\mathrm{RGO}$ from room temperature to $800^{\circ} \mathrm{C}$ is around $30 \%$.

\section{Conclusions}

In conclusion, the main objectives for the new oxidation temperature to prepare high quality graphene oxide and a new chemical reduction reagent of lithium triethylborohydride $\left(\mathrm{LiEt}_{3} \mathrm{BH}\right)$ were achieved. Based on Hummers method, the graphite oxidation temperature could be increased from $35^{\circ} \mathrm{C}$ to $50^{\circ} \mathrm{C}$, and the second high-temperature step could be completely removed. As with other preparation methods, the synthesized MTH-GO contains different types of functional groups consisting of hydroxyl, carbonyl, and epoxide groups. Lithium triethylborohydride was demonstrated as an effective alternative reagent for graphene oxide chemical reduction as demonstrated through AFM, SEM/EDS, UVVis, FTIR, Raman, and TGA characterization.

\section{Highlights}

Note the following highlights:

(i) increased temperature $\left(50^{\circ} \mathrm{C}\right)$ for Hummers' method to synthesize graphene oxide;

(ii) spectral analysis on the graphene oxide by different methods;

(iii) a new procedure for the reduction of graphene oxide by lithium triethylborohydride shown to be effective.

\section{Conflict of Interests}

The authors declare that there is no conflict of interests regarding the publication of this paper.

\section{Acknowledgments}

Jianyong Jin and Neil Broderick would like to thank The University of Auckland Faculty Research Development Fund (FRDF) Project no. 3702174 for their financial assistance. Jenny Malmström acknowledges the financial support from the MacDiarmid Institute for Advanced Materials and Nanotechnology. Guangyuan Xu is also grateful to Dr. Zoran Zujovic for assistance on solid state ${ }^{13} \mathrm{C}$ NMR, Dr. Michel Nieuwoudt for Raman, Ms. Catherine Hobbis for SEM/EDS, Dr. Xiaobo Ding, and Mr. Radesh Singh. All the authors thank their colleagues, Walt Wheelwright, Velram Balaji Mohan, Christopher Wilcox, Hong Kang, Alissa Hackett, Eddie Chan, Jian Zhang, James Wu, Zhixiu Wu, and Chao Liang, for their kind help.

\section{References}

[1] K. S. Novoselov, A. K. Geim, S. V. Morozov et al., "Electric field effect in atomically thin carbon films," Science, vol. 306, no. 5696, pp. 666-669, 2004.

[2] A. K. Geim and K. S. Novoselov, "The rise of graphene," Nature Materials, vol. 6, no. 3, pp. 183-191, 2007.

[3] A. K. Geim, "Graphene: status and prospects," Science, vol. 324, no. 5934, pp. 1530-1534, 2009.

[4] M. J. Allen, V. C. Tung, and R. B. Kaner, "Honeycomb carbon: a review of graphene," Chemical Reviews, vol. 110, no. 1, pp. 132145,2010

[5] S.-M. Paek, E. Yoo, and I. Honma, "Enhanced cyclic performance and lithium storage capacity of $\mathrm{SnO}_{2}$ /graphene nanoporous electrodes with three-dimensionally delaminated flexible structure," Nano Letters, vol. 9, no. 1, pp. 72-75, 2009.

[6] E. J. Yoo, J. Kim, E. Hosono, H.-S. Zhou, T. Kudo, and I. Honma, "Large reversible Li storage of graphene nanosheet families for use in rechargeable lithium ion batteries," Nano Letters, vol. 8, no. 8 , pp. 2277-2282, 2008. 
[7] L. L. Zhang, R. Zhou, and X. S. Zhao, "Graphene-based materials as supercapacitor electrodes," Journal of Materials Chemistry, vol. 20, no. 29, pp. 5983-5992, 2010.

[8] X. Wang, L. Zhi, and K. Müllen, "Transparent, conductive graphene electrodes for dye-sensitized solar cells," Nano Letters, vol. 8, no. 1, pp. 323-327, 2008.

[9] J. R. Potts, D. R. Dreyer, C. W. Bielawski, and R. S. Ruoff, "Graphene-based polymer nanocomposites," Polymer, vol. 52, no. 1, pp. 5-25, 2011.

[10] R. K. Joshi, P. Carbone, F. C. Wang et al., "Precise and ultrafast molecular sieving through graphene oxide membranes," Science, vol. 343, no. 6172, pp. 752-754, 2014.

[11] D. Cohen-Tanugi and J. C. Grossman, "Water desalination across nanoporous graphene," Nano Letters, vol. 12, no. 7, pp. 3602-3608, 2012.

[12] X. Li, W. Cai, J. An et al., "Large-area synthesis of high-quality and uniform graphene films on copper foils," Science, vol. 324, no. 5932, pp. 1312-1314, 2009.

[13] E. Sutter, P. Albrecht, and P. Sutter, "Graphene growth on polycrystalline Ru thin films," Applied Physics Letters, vol. 95, no. 13, Article ID 133109, 2009.

[14] Y. Hernandez, V. Nicolosi, M. Lotya et al., "High-yield production of graphene by liquid-phase exfoliation of graphite," Nature Nanotechnology, vol. 3, no. 9, pp. 563-568, 2008.

[15] I. K. Moon, J. Lee, R. S. Ruoff, and H. Lee, "Reduced graphene oxide by chemical graphitization," Nature Communications, vol. 1, article 73, 2010.

[16] X. F. Gao, J. Jang, and S. Nagase, "Hydrazine and thermal reduction of graphene oxide: reaction mechanisms, product structures, and reaction design," The Journal of Physical Chemistry C, vol. 114, no. 2, pp. 832-842, 2010.

[17] E. C. Salas, Z. Z. Sun, A. Lüttge, and J. M. Tour, "Reduction of graphene oxide via bacterial respiration," ACS Nano, vol. 4, no. 8, pp. 4852-4856, 2010.

[18] S. Stankovich, D. A. Dikin, R. D. Piner et al., "Synthesis of graphene-based nanosheets via chemical reduction of exfoliated graphite oxide," Carbon, vol. 45, no. 7, pp. 1558-1565, 2007.

[19] K. L. Ai, Y. L. Liu, L. H. Lu, X. L. Cheng, and L. H. Huo, "A novel strategy for making soluble reduced graphene oxide sheets cheaply by adopting an endogenous reducing agent," Journal of Materials Chemistry, vol. 21, no. 10, pp. 3365-3370, 2011.

[20] W. Chen, L. Yan, and P. R. Bangal, "Chemical reduction of graphene oxide to graphene by sulfur-containing compounds," Journal of Physical Chemistry C, vol. 114, no. 47, pp. 19885-19890, 2010.

[21] D. R. Dreyer, S. Murali, Y. W. Zhu, R. S. Ruoff, and C. W. Bielawski, "Reduction of graphite oxide using alcohols," Journal of Materials Chemistry, vol. 21, no. 10, pp. 3443-3447, 2011.

[22] H. B. Feng, R. Cheng, X. Zhao, X. F. Duan, and J. H. Li, "A low-temperature method to produce highly reduced graphene oxide," Nature Communications, vol. 4, article 1539, 2013.

[23] Z. J. Fan, K. Wang, T. Wei, J. Yan, L. P. Song, and B. Shao, "An environmentally friendly and efficient route for the reduction of graphene oxide by aluminum powder," Carbon, vol. 48, no. 5 , pp. 1686-1689, 2010.

[24] X. B. Fan, W. C. Peng, Y. Li et al., "Deoxygenation of exfoliated graphite oxide under alkaline conditions: a green route to graphene preparation," Advanced Materials, vol. 20, no. 23, pp. 4490-4493, 2008.
[25] Y. Z. Liu, Y. F. Li, Y. G. Yang, Y. F. Wen, and M. Z. Wang, "Reduction of graphene oxide by thiourea," Journal of Nanoscience and Nanotechnology, vol. 11, no. 11, pp. 10082-10086, 2011.

[26] M. J. Fernández-Merino, L. Guardia, J. I. Paredes et al., "Vitamin $\mathrm{C}$ is an ideal substitute for hydrazine in the reduction of graphene oxide suspensions," Journal of Physical Chemistry C, vol. 114, no. 14, pp. 6426-6432, 2010.

[27] C. Z. Zhu, S. J. Guo, Y. X. Fang, and S. J. Dong, "Reducing sugar: new functional molecules for the green synthesis of graphene nanosheets," ACS Nano, vol. 4, no. 4, pp. 2429-2437, 2010.

[28] Y. Chen, X. Zhang, P. Yu, and Y. Ma, "Stable dispersions of graphene and highly conducting graphene films: a new approach to creating colloids of graphene monolayers," Chemical Communications, no. 30, pp. 4527-4529, 2009.

[29] H.-J. Shin, K. K. Kim, A. Benayad et al., "Efficient reduction of graphite oxide by sodium borohydride and its effect on electrical conductance," Advanced Functional Materials, vol. 19, no. 12, pp. 1987-1992, 2009.

[30] A. Ambrosi, C. K. Chua, A. Bonanni, and M. Pumera, "Lithium aluminum hydride as reducing agent for chemically reduced graphene oxides," Chemistry of Materials, vol. 24, no. 12, pp. 2292-2298, 2012.

[31] H. C. Brown, S. C. Kim, and S. Krishnamurthy, "Selective reductions. 26. Lithium triethylborohydride as an exceptionally powerful and selective reducing agent in organic synthesis. Exploration of the reactions with selected organic compounds containing representative functional groups," Journal of Organic Chemistry, vol. 45, no. 1, pp. 1-12, 1980.

[32] S. Krishnamurthy and H. C. Brown, "Selective reductions. 31. Lithium triethylborohydride as an exceptionally powerful nucleophile-a new and remarkably rapid methodology for the hydrogenolysis of alkyl-halides under mild conditions," Journal of Organic Chemistry, vol. 48, no. 18, pp. 3085-3091, 1983.

[33] W. S. Hummers Jr. and R. E. Offeman, "Preparation of graphitic oxide," Journal of the American Chemical Society, vol. 80, no. 6, p. 1339, 1958.

[34] Z. T. Luo, Y. Lu, L. A. Somers, and A. T. C. Johnson, "High yield preparation of macroscopic graphene oxide membranes," Journal of the American Chemical Society, vol. 131, no. 3, pp. 898899, 2009.

[35] D. C. Marcano, D. V. Kosynkin, J. M. Berlin et al., "Improved synthesis of graphene oxide," ACS Nano, vol. 4, no. 8, pp. 48064814, 2010.

[36] D. A. Dikin, S. Stankovich, E. J. Zimney et al., "Preparation and characterization of graphene oxide paper," Nature, vol. 448, no. 7152, pp. 457-460, 2007.

[37] C. K. Chua and M. Pumera, "Chemical reduction of graphene oxide: a synthetic chemistry viewpoint," Chemical Society Reviews, vol. 43, no. 1, pp. 291-312, 2014.

[38] W. Gao, L. B. Alemany, L. Ci, and P. M. Ajayan, "New insights into the structure and reduction of graphite oxide," Nature Chemistry, vol. 1, no. 5, pp. 403-408, 2009.

[39] K. Zhang, L. Wang, Z. Hu, F. Cheng, and J. Chen, "Ultrasmall Li2S nanoparticles anchored in graphene nanosheets for highenergy lithium-ion batteries," Scientific Reports, vol. 4, article 6467, 2014

[40] W. Cai, R. D. Piner, F. J. Stadermann et al., "Synthesis and solidstate NMR structural characterization of ${ }^{13} \mathrm{C}$-labeled graphite oxide," Science, vol. 321, no. 5897, pp. 1815-1817, 2008.

[41] H. Wahab, G. Xu, C. Jansing et al., "Signatures of different carbon bonds in graphene oxide from soft x-ray reflectometry," X-Ray Spectrometry, vol. 44, no. 6, pp. 468-473, 2015. 
[42] R. Rozada, J. I. Paredes, M. J. López et al., "From graphene oxide to pristine graphene: revealing the inner workings of the full structural restoration," Nanoscale, vol. 7, no. 6, pp. 2374-2390, 2015.

[43] S. F. Pei and H.-M. Cheng, "The reduction of graphene oxide," Carbon, vol. 50, no. 9, pp. 3210-3228, 2012.

[44] D. Li, M. B. Müller, S. Gilje, R. B. Kaner, and G. G. Wallace, "Processable aqueous dispersions of graphene nanosheets," Nature Nanotechnology, vol. 3, no. 2, pp. 101-105, 2008.

[45] C. Zhang, D. M. Dabbs, L. Liu, I. A. Aksay, R. Car, and A. Selloni, "Combined effects of functional groups, lattice defects, and edges in the infrared spectra of graphene oxide," The Journal of Physical Chemistry C, vol. 119, no. 32, pp. 18167-18176, 2015.

[46] Y. Zhou, Q. Bao, L. A. L. Tang, Y. Zhong, and K. P. Loh, "Hydrothermal dehydration for the "green" reduction of exfoliated graphene oxide to graphene and demonstration of tunable optical limiting properties," Chemistry of Materials, vol. 21, no. 13, pp. 2950-2956, 2009. 

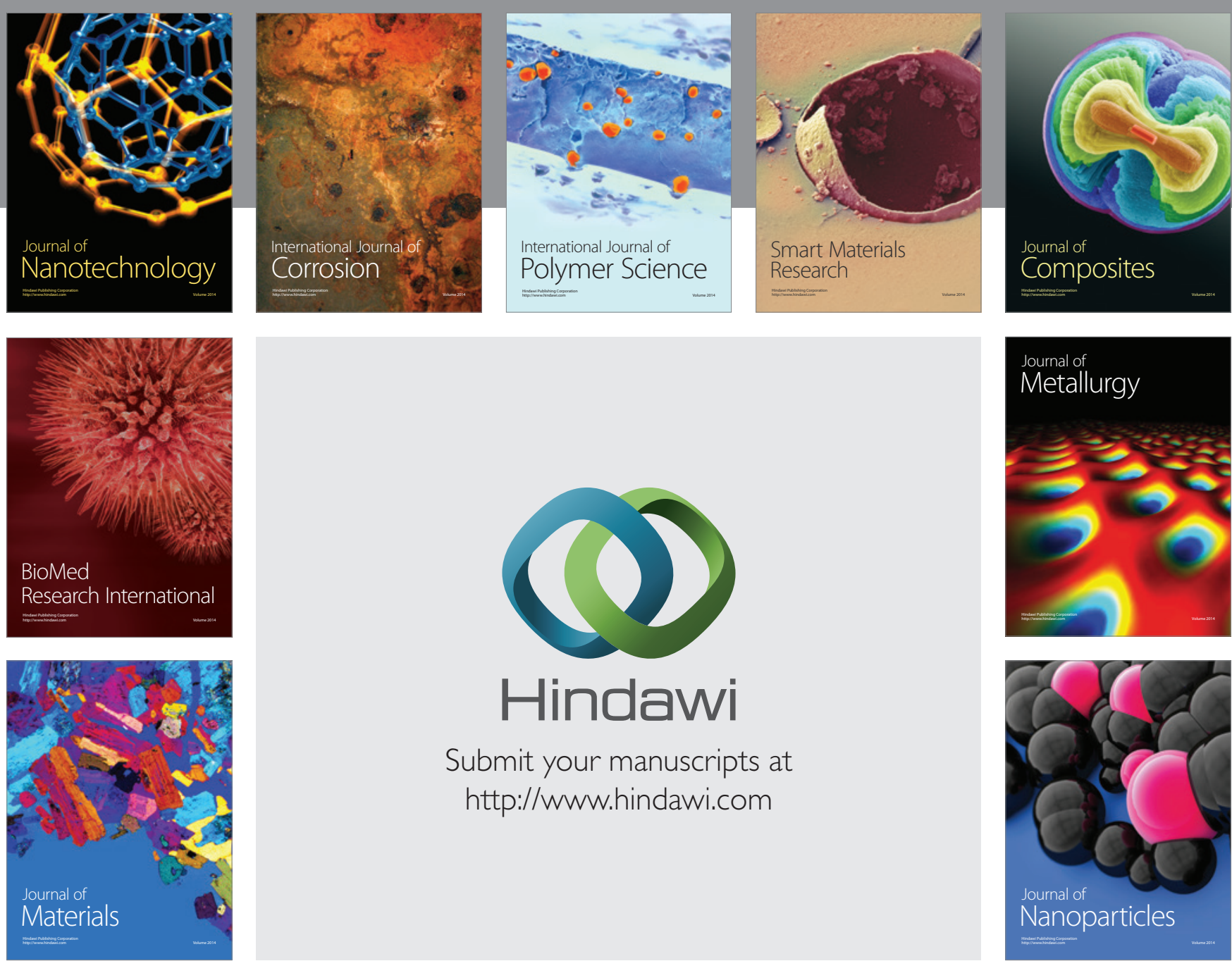

\section{Hindawi}

Submit your manuscripts at

http://www.hindawi.com

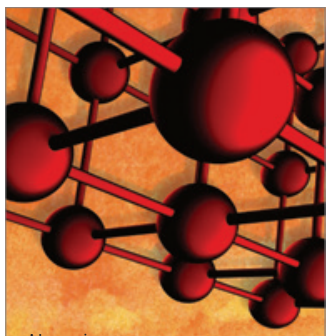

Materials Science and Engineering
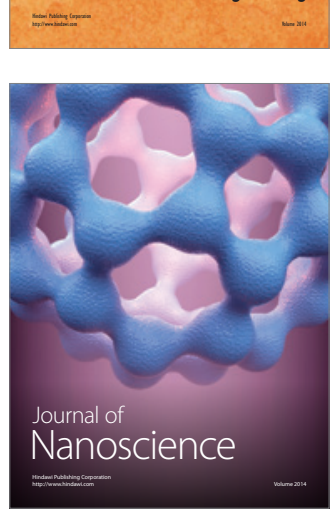
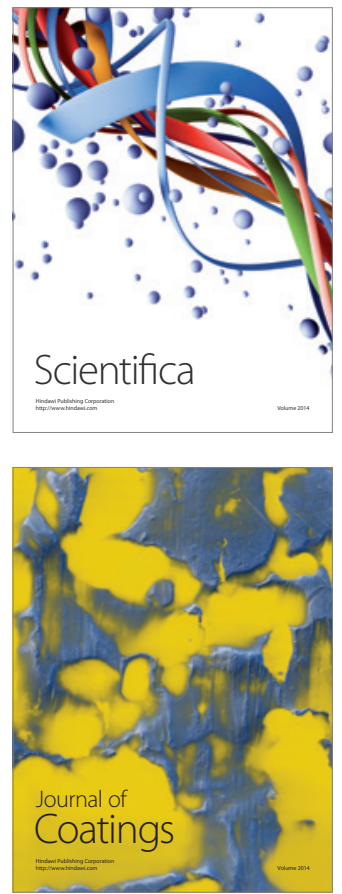
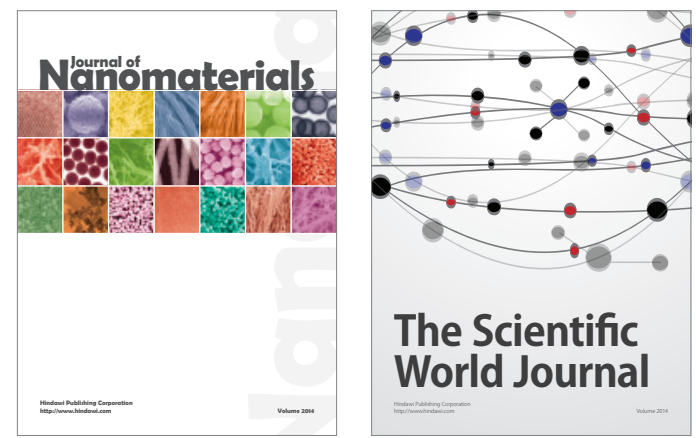

The Scientific World Journal
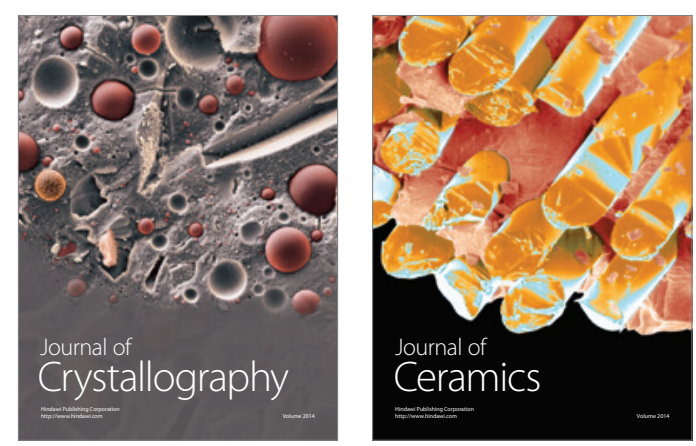
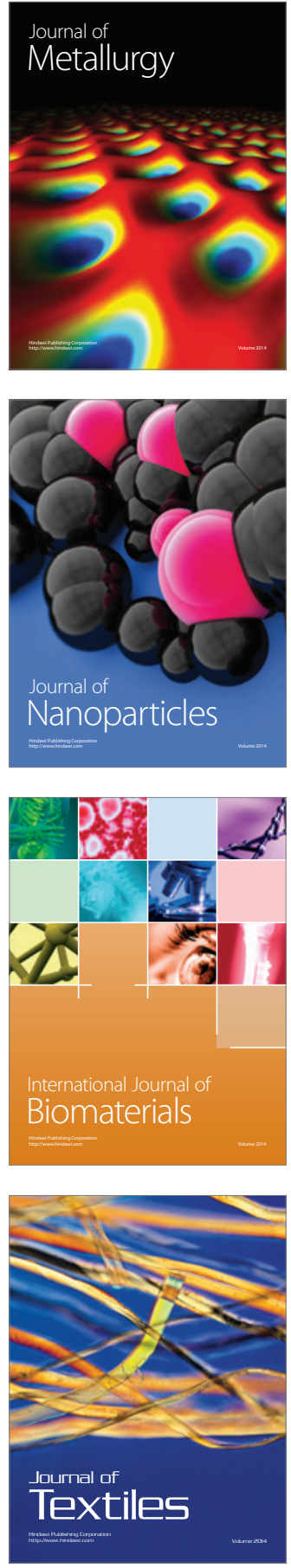